INTER NATIONAL MONETARY FUND
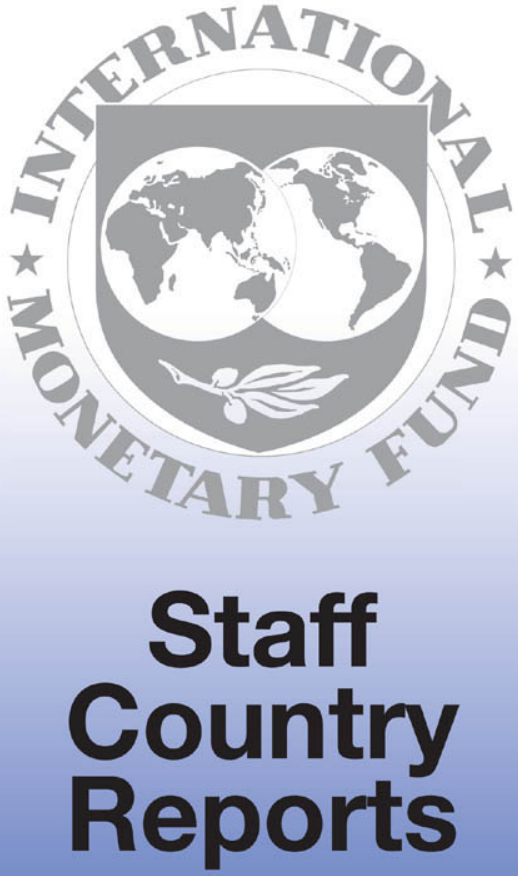


\section{Grenada: Poverty Reduction Strategy Paper-Preparation Status Report}

Poverty Reduction Strategy Papers (PRSPs) are prepared by member countries in broad consultation with stakeholders and development partners, including the staffs of the World Bank and the IMF. Updated every three years with annual progress reports, they describe the country's macroeconomic, structural, and social policies in support of growth and poverty reduction, as well as associated external financing needs and major sources of financing. This country document for Grenada, dated June 20, 2008, is being made available on the IMF website by agreement with the member country as a service to users of the IMF website.

Copies of this report are available to the public from

International Monetary Fund • Publication Services

$70019^{\text {th }}$ Street, N.W. • Washington, D.C. 20431

Telephone: (202) 623-7430 • Telefax: (202) 623-7201

E-mail: publications@imf.org • Internet: http://www.imf.org

\section{International Monetary Fund Washington, D.C.}


This page intentionally left blank

CInternational Monetary Fund. Not for Redistribution 
St. George's, Grenada

June 20, 2008

Mr. Dominique Strauss-Kahn

Managing Director

International Monetary Fund

Washington, D.C. 20431

Dear Mr. Strauss-Kahn:

The attached report outlines the status of the Government of Grenada's Poverty Reduction Strategy Paper which is expected to be finalized by November 2009.

Sincerely yours,

/s/

Honorable Keith Mitchell

Prime Minister and Minister of Finance

Attachment 


\section{Preparation Status REPORT FOR THE PRSP}

\section{Introduction}

The Government of Grenada submitted its Interim Poverty Reduction Strategy Paper (I-PRSP) to the Boards of the IMF and the World Bank in March 2006. In that document, the government presented a limited assessment of the poverty situation in Grenada using available data, which mainly predated the 2004-05 hurricanes, and outlined an interim medium- and long-term strategy to tackle it.

The Executive Boards of both the World Bank and the International Monetary Fund, as well as the staffs of the two institutions have given us valuable feedback on our interim strategy paper. In particular, the Joint Staff Assessment emphasized the need for strengthening the policy focus by including the link between policy and resource use and elaborating a clear framework for the coordination and monitoring of the strategy. It also emphasized the importance of using more recent poverty assessment surveys in developing the PRSP. This would strengthen the poverty diagnostics, allowing a better understanding of the determinants of, and regional distribution of poverty, and evaluation of the impact of policies designed to reduce poverty.

\section{Status of the Poverty Reduction Strategy Paper}

At the time the paper was submitted, it was envisaged that a full PRSP would be finalized by the end of 2006. While we have made substantial progress in developing many of the areas outlined in the I-PRSP and issues raised in the consultation process, the full PRSP has not yet been completed. We have completed a National Strategic Development Plan (NSDP), which was approved by Parliament in mid-2007, that sets out strategies and action plans to achieve the government's objectives.

While recognizing the advantages of having a finalized poverty reduction strategy in place, the government of Grenada has considered it important that additional time be taken-up to finalize the report for three main reasons. First, the government expects to draw on the ongoing Country Poverty Assessment (CPA) in the choice of priorities for the PRSP. Second, the government expects the PRSP to guide its policies over the medium term and, in consequence, wants it to cover all of the areas that are relevant for its reform agenda. Finally, in addition to the significant participatory and consultative process during the preparation of the NSDP, it will be necessary to undertake some additional consultations in light of the new poverty data and identified poverty reduction priorities and programs.

We aim to transform the NSDP into a full PRSP document. At this stage, we are waiting the findings from the CPA, which is expected to be completed in December 2008, and intend to work with the World Bank with the aim of developing a full PRSP by November 2009. 


\section{Issues Raised in the Joint Staff Assessment}

The PRSP will try to address many of the issues that were raised in the staff's joint assessment. In particular:

- In the area of poverty diagnostics, we intend to provide more detailed discussion of poverty based on updated poverty data. We will use the findings of the CPA to strengthen the poverty diagnostics and guide policies for poverty reduction. We also intend to use CPA to better target and rationalize social safety net measures in line with the government's broader poverty reduction objectives.

- We intend to discuss the main parameters of the macroeconomic framework and the links between this and the existing poverty alleviating programs. In particular, the PRSP will describe the links between poverty, growth and unemployment and the economic growth required to advance the social agenda. It will also clearly define priority poverty-reducing expenditures in the budget framework.

- We will provide more detailed sectoral strategies based on an updated poverty analysis. We also intend to make use of existing sectoral studies, such as risk and vulnerability assessments, and agreed structural reforms in the PRGF Arrangement, including action plans to improve the business climate. We will articulate the links between specific social problems, poverty reduction objectives, and structural reforms envisaged under the PRGF Arrangement.

- In the area of costing of initiatives, we will evaluate the full costs of social policies and programs, relate them to the budgetary envelope, and identify associated recurrent costs. This would also include an assessment of the need for, and availability of, financial resources. In addition, we intend to make the reforms operational and monitorable through measurable targets and easy-to-monitor indicators. Given institutional capacity and financial constraints, we intend to rationalize the various targets and indicators in the NSDP.

\section{New timeline}

Owing to delays in completing the CPA, and the need to develop multisectoral policies that capture the priorities for the PRSP and conduct additional consultations, we expect the PRSP to be finalized by November 2009. We intend to build on the work, including the consultative process, that was under undertaken for the NSDP. 